American Journal of Agricultural and Biological Sciences 5 (2): 222-227, 2010

ISSN 1557-4989

(C) 2010 Science Publications

\title{
Effects of Supplemental Lysine and Methionine on Growth Performance and Body Composition for Grass Carp (Ctenopharyngodon idella)
}

\author{
Hui Jun Yang, Yong Jian Liu, Li Xia Tian, Gui Ying Liang and Hao Ran Lin \\ Provincial Key Laboratory for Aquatic Economic Animals, Institute of Aquatic Economic Animals, \\ School of Life Sciences, Sun Yat-Sen University, Guangzhou 510275, PR China
}

\begin{abstract}
Problem statement: The utilization of crystalline amino acids was detected for growth performance and body composition of juvenile grass carp (Ctenopharyngodon idella). Approach: LLysine sulphate and Methionine Hydroxy Analog-Ca (MHA-Ca) were selected for determination. Two diets were formulated with or without amino acids supplementation. Each diet was assigned to 10 tanks in a completely randomized design for 8 weeks. Results: The results demonstrated that the final weight, Weight Gain (WG) and Protein Retention (PR) of the fish fed diet with supplemental lysine and methionine were significantly higher, while the Feed Conversion Ratio (FCR) were significantly lower in comparison with the reference group. The Condition Factor (CF) of the fish fed diet with lysine and methionine supplementation were significantly higher than the reference group $(\mathrm{p}<0.05)$. However, the Viscera Somatic Index (VSI), Hepato Somatic Index (HSI) and Intra Peritoneal Fat Ratio (IPFR) of the tested group were markedly lower $(\mathrm{p}<0.05)$. Whole body moisture and muscle protein content of the tested fish significantly increased, while the lipid level of whole body significantly decreased $(p<0.05)$ with the supplementation of lysine and methionine. Conclusion: Results of the present investigation demonstrate significant improvement of growth and feed utilization of grass carp can be achieved by L-Lysine sulphate and MHA-Ca supplementation. WG and PR of the tested group improved $11.4 \%$ and $8.3 \%$ respectively, while FCR decreased $9.6 \%$ in comparison with the reference group $(\mathrm{p}<0.05)$.
\end{abstract}

Key words: Ctenopharyngodon idella, lysine, methionine, growth performance

\section{INTRODUCTION}

As the largest aquaculture industry of finfish in China (Lin, 1991), the improvement of growth performance for grass carp (Ctenopharyngodon idella) is highly concerned by the feed companies and nutritional scientists. Among all the nutrients affecting the growth of grass carp, dietary protein is one of the most important (Wang et al., 2005) especially the amino acid profile of dietary protein which plays crucial role for the increase of protein retention and flesh quality for this species. With the steady improvement of the price of protein sources such as fishmeal and soybean meal, the protein quality of grass carp commerial feed remarkably declined in the recent years which indicates the percent of essential amino acids to dietary protein decreased (Wang et al., 2005).

As the most essential amino acids for grass carp (Wang et al., 2005) lysine and methionine levels can no longer satisfy the requirements in the commerial diets of grass carp, which caused the crystalline lysine and methionine supplementation become a hot persue among the aquaculture technologists. However, the utilization of crystalline amino acids for aquatic animals was influenced by fish species, feed nutritional composition, amino acid leaching (Liu et al., 1999, 2002; Wilson et al., 1980; Kornack and Rakic, 2001) and disproportionate absorption rates compared with intact protein (Yamada et al., 1981; Murai et al., 1982; Ronnestad et al., 2000). Liu et al. (1999; 2002) studied the pre-coated lysine supplementation for growth of grass carp and demonstrated the leaching and faster absorption of crystalline amino acid was the main reason which explains its restricted utilization by this species.

In the cultivating practice of grass carp in China, L-Lysine $\mathrm{HCl}$ was normally selected by feed producers. However, its relatively higher water solubility compared with more stable L-Lysine sulphate restricts its further application in the cost-effective aquatic feed.

Corresponding Author: Hao Ran Lin, Provincial Key Laboratory for Aquatic Economic Animals,

Institute of Aquatic Economic Animals and Guangdong, Sun Yat-Sen University, Guangzhou 510275, PR China 
As a new form of methionine product, Methionine Hydroxy Analog-Ca (MHA-Ca) can be easily digested by animal tissue after been absorbed in the blood and quickly transferred to L-Methionine which consequently Take part in the organic metabolism. In recently years, MHA-Ca tends to replace traditional methionine product with its potential effectiveness in aquaculture industry. Studies in our laboratory demonstrated that significant improvement of growth can be achieved by L-Lysine sulphate and MHA-Ca supplementation in tilapia and white shrimp (unpublished data).

The purpose of this investigation was to determine the effects of supplemental L-Lysine sulphate and MHA-Ca on growth performance and body composition for grass carp (Ctenopharyngodon idella) reared in a controlled environment.

\section{MATERIALS AND METHOIDS}

Diet preparation: Prior to use, all feed ingredients were analyzed for their proximate composition and the data obtained were used as a basis for making the required formulation. Two diets were formulated in this experiment, containing 1 reference diet and 1 tested diet. Formulation and proximate analysis (Association of Official Analytical Chemists, 1984) of the diets are given in Table 1 and 2 . The diet ingredients including cottonseed meal, rapeseed meal, wheat flour, wheat bran, full-fat rice bran, defatted rice bran and $\mathrm{Ca}\left(\mathrm{H}_{2} \mathrm{PO}_{4}\right)_{2} \cdot \mathrm{H}_{2} \mathrm{O}$ were provided by Shunde Libao Feed Co., Ltd. The vitamin and mineral premix, choline chloride and L-Lysine sulphate were provided by Guangzhou Ashare Aquatech Co., Ltd. Methionine hydroxy analog-Ca was provided by Novus International Trading (Shang Hai) Co., Ltd.

All dry ingredients were thoroughly mixed using a dough mixer, after which oil was added slowly while mixing was continuing. Then deionized water (300 mL kg-1 dry ingredients mixture) was slowly blended into the mixture, resulting in suitably textured dough. The diets were produced in a noodle-like shape of $1.5 \mathrm{~mm}$ in diameter using a twin-screw extruder (Institute of Chemical Engineering, South China University of Technology, Guangzhou, PR China). Then the diets were pelletized, dried at room temperature for $24 \mathrm{~h}$ sieved and stored at $-20^{\circ} \mathrm{C}$ until fed.

Experimental fish: Juvenile grass carp (Ctenopharyngodon idella) were obtained from our own fish farm and maintained at the Aquatic Economic Animals Research Laboratory, Sun Yat-Sen University
(Guang Zhou, China). Before initiation of the feeding trials, fish were acclimated to laboratory conditions for 2 weeks by feeding the reference diet; Fish were selected according to the health condition and body weight and individually weighed. The initial body weight averaged $6.85 \pm 0.03 \mathrm{~g}$ (mean $\pm \mathrm{SD}$ ). Sampled fish were not fed for $24 \mathrm{~h}$ prior to the initiation of the growth trials.

Table 1: Composition and proximate analysis of the experimental diets

\begin{tabular}{lcc}
\hline Ingredients $\left(\mathrm{g} \mathrm{kg}^{-1}\right)$ & Reference group & Tested group \\
\hline Canola rapeseed meal & 250.0 & 250.0 \\
Cottonseed meal & 150.0 & 150.0 \\
Wheat flour & 200.0 & 200.0 \\
Defatted rice bran & 138.0 & 138.0 \\
Full-fat rice bran & 80.0 & 80.0 \\
Wheat bran & 140.0 & 140.0 \\
Calcium phosphate dibasic & 20.0 & 20.0 \\
L-Lysine sulphate $(50 \%)$ & 0.0 & 3.0 \\
MHA-Ca $(84 \%)^{1}$ & 0.0 & 0.5 \\
Vitamin mix & 5.0 & 5.0 \\
Mineral mix & 5.0 & 5.0 \\
Choline chloride & 2.0 & 2.0 \\
Sodium chloride & 5.0 & 5.0 \\
Zeolite powder & 5.0 & 1.5 \\
Proximate composition & & \\
Dry matter & 922.0 & 915.0 \\
Ash (g kg $\mathrm{gry} \mathrm{matter}^{-1}$ & 97.0 & 97.0 \\
Crude lipid $\left(\mathrm{g} \mathrm{kg}^{-1} \mathrm{dry}^{3}\right.$ matter) & 17.9 & 16.6 \\
Crude protein $\left(\mathrm{g} \mathrm{kg}^{-1}\right.$ dry matter) & 267.4 & 269.1 \\
Total energy $\left(\mathrm{Kcal} \mathrm{kg}^{-1}\right)$ & 3872.0 & 3902.0 \\
\hline
\end{tabular}

${ }^{1}$ : Methionine hydroxy analog-Ca; ${ }^{2}:$ Vitamin $\left(\mathrm{mg} \mathrm{kg}^{-1}\right.$ diet $)$ : Thiamin 3 ; riboflavin 8 ; pyridoxine 4 ; cyanocobalamin 2; retinol $1500 \mathrm{IU}$; cholecalciferol 2000IU; all-rac-a-tocopherol 40; menadione 6; nicotinic acid 12; folic acid 2; Ca pantothenate 25; biotin 2; inositol 50; ${ }^{3}$ : Mineral (mg kg${ }^{-1}$ diet): $\mathrm{MgSO}_{4} \cdot 7 \mathrm{H}_{2} \mathrm{O} 315 ; \mathrm{ZnSO}_{4} \cdot 7 \mathrm{H}_{2} \mathrm{O} 285$; $\mathrm{CaHPO}_{4} \cdot 2 \mathrm{H}_{2} \mathrm{O} 250 ; \mathrm{FeSO}_{4} \cdot 7 \mathrm{H}_{2} \mathrm{O} 200 ; \mathrm{MnSO}_{4} \cdot \mathrm{H}_{2} \mathrm{O} 25 ; \mathrm{CoSO}_{4} \cdot 7 \mathrm{H}_{2} \mathrm{O}$ $25 ; \mathrm{Ca}\left(\mathrm{IO}_{3}\right)_{2} 25 ; \mathrm{CuSO}_{4} \cdot 5 \mathrm{H}_{2} \mathrm{O} 15 ; \mathrm{Na}_{2} \mathrm{SeO}_{3} 10$

Table 2: Amino acid composition $\left(\mathrm{g} \mathrm{kg}^{-1}\right.$ diet) of experimental diets

\begin{tabular}{lcc}
\hline Amino acids & Reference group & Tested group \\
\hline Essential amino acids & & \\
Arginine & 17.8 & 17.9 \\
Histidine & 6.2 & 6.0 \\
Leucine & 16.1 & 16.1 \\
Isoleucine & 9.4 & 9.4 \\
Lysine & 10.5 & 11.6 \\
Methionine & 3.9 & $3.9(4.32)^{1}$ \\
Phenylalanine & 10.9 & 10.9 \\
Threonine & 8.2 & 8.4 \\
Valine & 12.9 & 13.1 \\
Non-essential amino acids & & \\
Aspartic acid & 18.0 & 18.3 \\
Glutamic acid & 49.2 & 48.7 \\
Serine & 7.6 & 7.6 \\
Proline & 14.1 & 14.1 \\
Glycine & 11.4 & 11.4 \\
Alanine & 10.9 & 10.8 \\
Tyrosine & 5.2 & 5.1 \\
Cystine & 1.7 & 1.7 \\
\hline
\end{tabular}

${ }^{1}$ : As an analog of methionine, MHA-Ca can not be detected by the amino acid analyzer, so calculated value (4.32) was also presented 
They were randomly allocated to 20 tanks $(300 \mathrm{~L})$ with 30 fish per tank. Each diet was assigned to 10 tanks in a completely randomized design. The experiment lasted for 8 weeks during which fish were hand-fed twice a day at 09:00 and 15:00 $\mathrm{h}$ for every 2 weeks, experimental fish were weighted and counted to check their growth, survival and adjust feeding levels. The daily feeding rate was about $5 \%$.

Rearing system: The experimental system was equipped with coral-sand filter $(25 \mathrm{~cm}$ thickness) and second primary biological filter, low-pressure electrical blowers provided aeration via air stones and Dissolved Oxygen (DO) levels were maintained at or near to saturation. Water temperature and quality parameters were monitored during the experimental period. Water temperature ranged between 23 and $29^{\circ} \mathrm{C}$; dissolved oxygen $>8 \mathrm{mg} \mathrm{L} \mathrm{L}^{-1}$; $\mathrm{pH} 7.4$; total ammonia-nitrogen $<0.4 \mathrm{mg} \mathrm{L}^{-1}$; fish were subjected to a natural photoperiod regime.

Sample collection and chemical analysis: At the beginning of the experiment, 8 fish were randomly captured and kept frozen for chemical analysis of whole body composition. 47 fish from the same initial pool were also withdrawn to weigh the viscera for calculating Viscera Somatic Index (VSI), after which fish were slaughtered and the white muscle were collected for analysis.

At the termination of the growth trial, fish were sampled after fasting for $24 \mathrm{~h}$ eight fish from each tank were randomly selected for proximate analysis, two of which were used for whole body composition and six for white muscle and liver composition. After being anaesthetized with tricaine Methane Sulphonate (MS222) (50 mg L ${ }^{-1}$ ), fish were individually weighed and measured. The digestive glands and white muscle were rapidly removed. The viscera, liver and intraperitoneal fat were weighed for calculation of Hepato Somatic Index (HSI), VSI and Intra Peritoneal Fat Ratio (IPFR).

Diets, fish whole body and tissues were analyzed for proximate composition according to the procedures of Association of Official Analytical Chemists (Association of Official Analytical Chemists, 1984). Moisture was analyzed by drying at $105^{\circ} \mathrm{C}$ for $24 \mathrm{~h}$ Protein, lipid and ash contents of diets and samples were analyzed by the Kjeldhal method with Tecator Kjelte (1030-Auto-analyzer, Tecator, Sweden), Soxhlet Extraction with Tecator Soxtem (Soxtec System HT6, Tecator, Sweden) and combustion at $550^{\circ} \mathrm{C}$ for $24 \mathrm{~h}$ respectively. Gross energy was obtained by means of an adiabatic bomb calorimeter (model WHR-15; Changsha, China, calibrated with benzoic acid). Amino acid compositions of diets were analyzed by a commercial laboratory using an automatic amino acid analyzer (Hitachi, Model 835-50, Hitachi, Tokyo, Japan).

Data calculation and statistical analysis: The following parameters were calculated for evaluation of fish performance:

- $\mathrm{WG}(\%)=100 \times($ final mean weight-initial mean weight)/initial mean weight $(\mathrm{g})$

- $\operatorname{Survival}(\%)=100 \times$ final fish number/initial fish number

- Protein Retention $(\mathrm{PR})=$ fish protein gain $(\mathrm{g}) /$ protein intake $(\mathrm{g})$

- $\quad \mathrm{FCR}=$ dry feed intake (g)/fish weight gain (g)

- Condition Factor $(\mathrm{CF})=100 \times$ body weight $(\mathrm{g}) /$ body length $(\mathrm{cm})^{3}$

- $\quad \mathrm{VSI}=100 \times$ viscera weight/whole body weight

- $\quad \mathrm{IPFR}=100 \times \mathrm{IPF}$ weight $/$ whole body weight

- $\mathrm{HSI}=100 \times$ liver weight/whole body weight

The results were presented as means \pm SD, unless otherwise specified. Data were statistically analyzed by Student t-test using the software of the SPSS for Windows (version 13.0, USA). Where significant differences were found $(\mathrm{p}<0.05)$, a Duncan New Multiple Range Test was used to rank the groups (Duncan, 1955).

\section{RESULTS}

Biological performance of fish: The growth performance of grass carp fed the experimental diets were presented in Table 3. The final mean weight, WG and PR of the fish fed diet with supplemental lysine and methionine were significantly higher, while the FCR were significantly lower in comparison with the reference group.

Table 3: Growth performance and feed utilization of juvenile grass carp fed experimental diets at the end of the growth trial

\begin{tabular}{lllllll}
\hline Diets & $\mathrm{IBW}^{1}$ & $\mathrm{FBW}^{2}$ & Survival & $\mathrm{WG}^{3}$ & $\mathrm{FCR}^{4}$ & $\mathrm{PR}^{5}$ \\
\hline Reference group & $6.86 \pm 0.04$ & $20.4 \pm 0.62^{\mathrm{a}}$ & $99.6 \pm 1.13$ & $198.2 \pm 8.9^{\mathrm{a}}$ & $1.88 \pm 0.07^{\mathrm{b}}$ & $28.52 \pm 1.09^{\mathrm{a}}$ \\
Tested group & $6.85 \pm 0.02$ & $22.0 \pm 0.94^{\mathrm{b}}$ & $99.6 \pm 1.13$ & $220.8 \pm 14.0^{\mathrm{b}}$ & $1.70 \pm 0.11^{\mathrm{a}}$ & $30.88 \pm 2.36^{\mathrm{b}}$ \\
\hline
\end{tabular}

Values (mean \pm SD of 10 replications) in the same column with different superscripts are significantly different $(\mathrm{p}<0.05) .{ }^{1}:$ IBW, initial mean body weight $(\mathrm{g}){ }^{2}$ : FBW, final mean body weight $(\mathrm{g}) ;{ }^{3}: \mathrm{WG}$, weight gain $(\%) ;{ }^{4}: \mathrm{FCR}$, feed conversion ratio; ${ }^{5}: \mathrm{PR}$, protein retention 
Am. J. Agri. \& Biol. Sci., 5 (2): 222-227, 2010

Table 4: Slaughter variables of juvenile grass carp fed experimental diets at the end of the growth trial

\begin{tabular}{lllll}
\hline & $\mathrm{CF}^{1}$ & $\mathrm{VSI}^{2}$ & $\mathrm{HSI}^{3}$ & $\mathrm{IPFR}^{4}$ \\
\hline Initial & $1.90 \pm 0.12$ & $7.72 \pm 1.00$ & - & - \\
Reference group & $1.81 \pm 0.03^{\mathrm{a}}$ & $8.80 \pm 0.35^{\mathrm{b}}$ & $1.85 \pm 0.17^{\mathrm{b}}$ & $1.27 \pm 0.14^{\mathrm{b}}$ \\
Tested group & $1.88 \pm 0.04^{\mathrm{b}}$ & $8.23 \pm 0.49^{\mathrm{a}}$ & $1.63 \pm 0.15^{\mathrm{a}}$ & $1.08 \pm 0.16^{\mathrm{a}}$ \\
\hline Val
\end{tabular}

Values (mean \pm SD of 10 replications) in the same row with different superscripts are significantly different $(\mathrm{p}<0.05) .{ }^{1}:$ Condition factor; ${ }^{2}:$

Viscerosomatic index; ${ }^{3}$ : Hepatosomatic index; ${ }^{4}$ : Intraperitoneal fat ratio

Table 5: Body composition $\left(\mathrm{g} \mathrm{kg}^{1}\right.$ of wet weight basis) in juvenile grass carp fed experimental diets at the end of the growth trial

\begin{tabular}{lllll}
\hline & Moisture & Lipid & Protein & Ash \\
\hline Whole body & & & & \\
Initial & 809 & 25.8 & 128.2 & 29.2 \\
Reference group & $759 \pm 3.6^{\mathrm{a}}$ & $61.6 \pm 3.0^{\mathrm{b}}$ & $138.1 \pm 2.9$ & $30.6 \pm 0.8$ \\
Tested group & $768 \pm 7.7^{\mathrm{b}}$ & $53.7 \pm 4.1^{\mathrm{a}}$ & $138.1 \pm 3.4$ & $30.2 \pm 1.1$ \\
White muscle & & & & 157.2 \\
Initial & 828 & 5.7 & $168.7 \pm 1.5^{\mathrm{a}}$ & 11.9 \\
Reference group & $803 \pm 2.6$ & $10.8 \pm 1.9$ & $170.7 \pm 1.9^{\mathrm{b}}$ & $11.5 \pm 0.4$ \\
Tested group & $804 \pm 2.7$ & $9.8 \pm 1.6$ & - & $11.9 \pm 1.5$ \\
Liver & & & & - \\
Reference group & $654 \pm 15.0$ & $144.1 \pm 14.2$ & - & - \\
Tested group & $662 \pm 15.7$ & $143.1 \pm 12.0$ & & \\
\hline
\end{tabular}

Values (mean \pm SD of 10 replications) in the same row with different superscripts are significantly different $(\mathrm{p}<0.05)$

Slaughter variables of fish: The slaughter variables were displayed in Table 4 . The CF of the fish fed diet with lysine and methionine supplementation were significantly higher, whereas the VSI, HSI and IPFR were markedly lower than the reference fish.

Proximate composition of fish: Proximate compositions of the experimental fish were shown in Table 5. Whole body moisture and lipid level of the tested fish were significantly higher and lower than the reference fish, respectively. White muscle protein level of tested fish displayed significantly higher values than the reference fish. However, insignificant differences were observed for other chemical composition of whole body, white muscle and liver.

\section{DISCUSSION}

In traditional experimental design of aquaculture nutrition, 3 replicate tanks for each treatment was usually selected by scientific investigators and achieved good results in some studies, especially in those with diet formulations showing more evident discrepancies in macronutrient levels. However, in some experiments with formulations different in micronutrients, such as feed additives, 3 parallels in each treatment is probably not enough to show statistical difference in results. Studies of amino acids supplementation in our laboratory indicated that insignificant difference on growth performance were obtained by feeding tilapia juveniles with 3 replicates in each group, while significant difference occurred by 10 parallels in each treatment (unpublished data). In order to show a clear result of Essential Amino Acids (EAA) supplementation for grass carp under the experimental condition, 10 parallels in each group were selected by the author in this investigation which partly explained the occurrence of significant difference in the results (Table 3).

The effects of essential amino acids supplementation for animal growth performance were markedly affected by the nutritional status of the diet, especially the protein and EAA levels as noted by (Yamamoto et al., 2005). In pig and poultry diets, (Verstegen and Jongbloed, 2003) reported the supplementation of EAA achieved significantly better growth and feed utilization compared with the reference diets without supplemented EAA when the dietary protein levels were much lower than their requirements. However, in fish diets, the supplementation of EAA to a low-protein diet is seldom reported by investigators. In channel .catfish (Li and Robinson, 1998) and rainbow trout (Yamamoto et al., 2005), researchers showed the supplementation of EAA in a insufficient protein diet improved the feed efficiency but did not enhance fish growth. In Asian sea bass, (Williams et al., 2001) demonstrated the crystalline-EAA supplementation to an EAA deficient diet increased fish growth and the response was more pronounced for the low protein diet. The protein and EAA requirements of juvenile grass carp have been established in our laboratory by (Wang, 2006) with optimal protein, lysine and methionine levels to be 391.4, 54.4 and $29.7 \mathrm{~g} \mathrm{~kg}^{-1}$ (on the basis of dietary protein), respectively. In the present experiment, the crude protein level of the reference diet was $267.4 \mathrm{~g}$ $\mathrm{kg}^{-1}$, the lysine and methionine levels were 10.5 and $3.9 \mathrm{~g} \mathrm{~kg}^{-1}$, corresponding to 39.3 and $14.6 \mathrm{~g} \mathrm{~kg}^{-1}$ of 
dietary protein, respectively. It is obvious the protein, lysine and methionine levels of the reference diet are further reduced from their requirements which mainly explained the significant improvement of WG and PR, as well as the apparent decrease of FCR in the tested group compared with the reference group (Table 3 ). The improved PR in this study is in agreement with (Yamamoto et al., 2005) who suggested the EAA supplementation to low-protein diets in rainbow trout improves dietary amino acid utilization and results in an increase of body protein deposition, as similarly noted in gilthead seabream (Peres and Oliva-Teles, 2009). Such advances in growth performance of grass carp was also observed in another study of channel catfish which reported the effect of supplemental lysine was more pronounced in $24 \%$ protein diets rather than in the 30\% protein diets (Bai and Gatlin, 1994).

Besides the nutritional status of the diets, the leaching of crystalline amino acids was also a major problem affecting its utilization by grass carp (Liu et al., 1999; 2002). The increase of WG and decrease of FCR fed supplemental lysine in a low-protein $(25 \%)$ practical diet for juvenile grass carp has also been reported by (Liu et al., 2002). However, in that experiment, both uncoated and pre-coated L-lysine were tested but significantly higher values of growth and feed utilization only appeared in the group with pre-coated lysine supplementation, while treatments of uncoated and deficient (reference) lysine diets presented no significant difference. In the present study, L-Lysine sulphate and MHA-Ca with markedly lower water solubility than their traditional products were selected, which in some extent diminished the influence of amino acid leaching on fish growth and achieved significant difference in results.

The slaughter variables and body composition of grass carp is another important aspect needed to pay attention in this experiment (Table 4 and 5). The significantly lower VSI, HSI, IPFR and whole body lipid, as well as the higher muscle protein of tested fish compared with the reference fish indicated a better health condition and higher economic value of grass carp were obtained by feeding supplemental EAA based on our experience. However, such result of IPFR and body lipid was contradictory with an earlier report of grass carp (Wang et al., 2005) and studies of red seabream and freshwater catfish (Chatzifotis et al., 1996; Tantikitti and Chimsung, 2001) which found higher body lipid content and IPFR occurred in the lysine supplemented groups. In those studies, high levels of crystalline lysine were added compared with the present experiment. The authors suggested the amino acids in excess from disproportionate absorption or the part of lysine beyond optimal level would be no longer used for transformation into protein or protein synthesis, but was consumed in catabolism and provided the carbon skeletons for lipid synthesis and deposited as tissue fat, mainly at mesentery. So the opposite results of IPFR and whole body lipid in the present study may be attributed to the insufficient supplementation of lysine and methionine which makes such metabolic pathway impossible and this can be confirmed by the markedly increased muscle protein level of the tested fish, as also noted by (Peres and Oliva-Teles, 2009) in gilthead seabream.

\section{CONCLUSION}

In conclusion, results of the present investigation demonstrate significant improvement of growth and feed utilization of grass carp can be achieved by LLysine sulphate and MHA-Ca supplementation. WG and PR of the tested group improved 11.4 and $8.3 \%$ respectively, while FCR decreased $9.6 \%$ in comparison with the reference group $(\mathrm{p}<0.05)$.

\section{REFERENCES}

Association of Official Analytical Chemists, (AOAC), 1984. Official Methods of Analysis. 14th Edn., AOAC, Arlington, VA., pp: 114.

Bai, S.C. and D.M. Gatlin, 1994. Effects of 1-lysine supplementation of diets with different protein levels and sources on channel catfish, Ictalurus punctatus (Rafinesque). Aquacult. Fish. Manage., 25: 465-474. DOI: $10.1111 / \mathrm{j} .1365-$ 2109.1994.tb00711.x

Chatzifotis, S., T. Takeuchi and T. Seikai, 1996. The effect of dietary carnitine supplementation on growth of red sea bream (Pagrus major) fingerlings at two levels of dietary lysine. Aquaculture, 147: 235-248. DOI: 10.1016/S00448486(96)01403-2

Duncan, D.B., 1955. Multiple-range and multiple F tests. $\quad$ Biometrics, 11: 1-42. http://www.garfield.library.upenn.edu/classics1977 /A1977DM02600001.pdf

Kornack, D. and P. Rakic, 2001. Cell proliferation without neurogenesis in adult primate neocortex. Science, 294: 2127-2130. DOI: 10.1126/science. 1065467

Li, M.H. and E.H. Robinson, 1998. Effects of supplemental lysine and methionine in low protein diets on weight gain and body composition of young channel catfish Ictalurus punctatus. Aquaculture, 163: 297-307. DOI: 10.1016/S00448486(98)00239-7 
Lin, D., 1991. Grass Carp, Ctenopharyngodon Idella. In: Handbook of Nutrient Requirements of Finfish, Wilson, R.P. (Ed.). CRC Press, Boca Raton, Florida, ISBN: 13: 9780849336287 , pp: 89-96.

Liu, Y.J., D.H. Liu, L.X. Tian and Y.M. Cao, 1999. Effect of fish food with coating and crystalline lysine on Ctenopharyngodon iedllus. J. Fish. China, 23: $52-53$.

http://d.wanfangdata.com.cn/ExternalResourcescxb200203011\%5e1.aspx

Liu, Y.J., L.X. Tian, D.H. Liu, G.Y. Liang and X.K. Zhao et al., 2002. Influence of practical diet supplementation with free or coated lysine on the growth, plasma free amino acids and protein synthesis rates in the muscle of Ctenopharyngodon idellus. J. Fish. China, 26: 252-258. http://d.wanfangdata.com.cn/Periodical_scxb20020 3011.aspx

Murai, T., T. Akiyama and T. Nose, 1982. Effects of casein coating on utilization of dietary amino acids by fingerling carp and channel catfish. Bull. Jap. Soc. Sci. Fish., 48: 787-792. http://rms1.agsearch.agropedia.affrc.go.jp/contents/ JASI/pdf/society/25-2148.pdf

Peres, H. and A. Oliva-Teles, 2009. The optimum dietary essential amino acid profile for gilthead seabream (Sparus aurata) juveniles. Aquaculture, 296: 81-86.

DOI: 10.1016/j.aquaculture.2009.04.046

Ronnestad, I., L.E.C. Conceicao, C. Aragao and M.T. Dinis, 2000. Free amino acids are absorbed faster and assimilated more efficienctly than protein in postlarval Senegal sole (Solea senegalensis). J. Nutr., $\quad$ 130: 809-2812. http://jn.nutrition.org/cgi/reprint/130/11/2809

Tantikitti, C. and N. Chimsung, 2001. Dietary lysine requirement of freshwater catfish (Mystus nemurus Cuv. and Val.). Aquac. Res., 32: 135-141. http://agri.wu.ac.th/Staff/AquaSci/Noppawan/Pdf0 2/page01.pdf
Verstegen, M.W.A. and A.W. Jongbloed, 2003. Crystalline Amino Acids and Nitrogen Emission. In: Amino Acids in Animal Nutrition, D'Mello, J.P.F. (Ed.), 2nd Edn., CABI Publishing, Wallingford, UK., ISBN: 085199654 X, pp: 449-458.

Wang, S., 2006. Studies on protein and essential amino acid requirements of grass carp, Ctenopharyngodon iedlla). Doctoral dissertation, sun yat-sen university, Guangzhou, PR China. http://dlib4.edu.cnki.net/kns50/

Wang, S., Y.J. Liu, L.X. Tian, M.Q. Xie and H.J. Yang et al., 2005. Quantitative dietary lysine requirement of juvenile grass carp Ctenopharyngodon idella. Aquaculture, 249: 419-429. DOI: 10.1016/j.aquaculture.2005.04.005

Williams, K., C. Barlow and L. Rodgers, 2001. Efficacy of crystalline and protein-bound amino acids for amino acid enrichment of diets for barramundi/Asian seabass (Lates calcarifer Bloch). Aquac. Res., 1: 415-429. http://d.wanfangdata.com.cn/NSTLQK_NSTL_QK 5509535.aspx

Wilson, R.P., W.E. Poe and E.H. Robinsin, 1980. Leucine, isoleucine, valine and histidine requirements of fingerling channel catfish. J. Nutr., 110: 627-633. http://jn.nutrition.org/cgi/reprint/110/4/627

Yamada, S., K.L. Simpson, Y. Tanaka and T. Katayama, 1981. Plasma amino acid changes in rainbow trout (Salmo gairdneri) force-fed casein and a corresponding amino acid mixture. Bull. Jap. Soc. Sci. Fish., 47: 1035-1040. http://rms1.agsearch.agropedia.affrc.go.jp/contents/ JASI/pdf/society/23-3606.pdf

Yamamoto, T., T, Sugita and H, Furuita, 2005. Essential amino acid supplementation to fish mealbased diets with low protein to energy ratios improves the protein utilization in juvenile rainbow trout Oncorhynchus mykiss. Aquaculture, 246: 379-391. DOI: 10.1016/j.aquaculture.2005.02.013 